\title{
STUDY OF MOLECULAR INTERACTION IN CERTAIN BINARY AND TERNARY LIQUID SYSTEM S BY EXPOSING IT TO ULTRASONIC FREQUENCY OF 2 MHz AT 293.15 K
}

\author{
M.Vijay Alexander ${ }^{1}$, S. Sasikumar ${ }^{2}$, G. Meenakshi ${ }^{3}$ \\ ${ }^{1}$ Assistant Professor of Physics in V.R.S. College of Engineering \& Technology, Arasur, Villupuram \\ ${ }^{2}$ Research Scholar in Karpagam University, Coimbatore \\ ${ }^{3}$ Associate Professor of Physics (Rtd.) in K.M.C.P.G.S, Government of Pondicherry, Pondicherry
}

\begin{abstract}
The essential frame work of manufacturing material is composed of scientific and practical interrelationship. It plays the role among the structure, structural properties and performance of all classes of materials that are potentially useful to the society. Even after manufacturing the materials further it is necessary to study the physical and chemical properties of those materials. One of such properties can be studied by exposing the liquid or solid materials to ultrasonic vibrations. In the liquid binary system chosen for this study is toluene with benzene, hexane, heptane and cyclohexane at temperature i.e. 293.15K. The experimental value of ultrasonic velocity and density of binary mixtures are taken from the work of P.S.Nikam etal' and the sample chosen is mainly due to the availability of the experimental data. The various acoustical parameters like ultrasonic velocity, percentage deviation, excess impedance, and excess velocity are calculated and obtained results are suitably interpreted. The ternary system chosen for this study are cyclohexane plus toluene plus 2-propanol, studied at 293.15K.The experimental value of ultrasonic velocity and density for this mixture has been taken from the work of G. Arul etal. The values of sound velocity have been evaluated theoretically using three different methods namely Nomoto, Van-deal and CFT. For both binary and ternary mixtures, the observed result shows that the Nomoto method seems to give good results for the evaluation of acoustical parameters compared to collision factor theory (CFT) and Van-deal's method.
\end{abstract}

Key Words: Binary system, Nomoto method, CFT method, Van-deal's Method.

\section{INTRODUCTION}

The essential frame work of manufacturing material is composed of the scientific and practical interpolation at play among the structure, structural properties and performance of all classes of materials that are potentially useful to the society. Even after manufacturing the materials, it is important that one has to analyze its physical and chemical properties. One such property can be investigated by exposing the liquid and solid materials to ultrasonic sound vibrations. Ultrasonic velocity measurements are widely used to study the physical and chemical behavior of liquid mixtures. In recent years a good amount of work has been done to correlate the experimental ultrasonic velocities with those computed theoretically using empirical and semi empirical relations [1-4]. Nomoto (1958) and Bhimseenachal etal (1962) made successful attempts to evaluate sound velocity on binary liquid mixtures. The free length theory (FLT) of Jacobson (1951, 1952, a, b) and Schaff's (1939) collision factor theory (CFT) have been used to predict intermolecular interactions between unlike molecules of mixtures. Several workers (Pandey etal 1977, 1978, Shukla and Dubey 1984 and Shukla etal (1971) found that FLT is better than CFT for theoretical evaluation of sound velocity whereas Mishra and Pandey (1977) observed that the CFT method is better than FLT for the fore said purpose. Shukla and Dubey (1984) found that the Van-Deal ideal mixing relations given minimum deviation. J.D. Pandey etal $^{5}$ found that ideal mixing relation gives the minimum deviation for all the systems except acetone.

These studies motivated the author to find the suitable theoretical method to evaluate the sound velocity in binary and ternary mixture using three different theoretical relations (Nomoto, Van-Deal and CFT) ${ }^{6}$.

\section{THEORETICAL CONSIDERATIONS}

Nomoto [6] suggested an empirical formula for sound velocity in binary liquid mixture as follows;

$$
U_{m}=\left(\frac{X_{1} R_{1}+X_{2} R_{2}}{X_{1} V_{1}+X_{2} V_{2}}\right)^{3}
$$

Van-Deal and Van-Deal [7] suggested the following relation for sound velocity $\mathrm{U}_{\mathrm{im}}$ as

$$
\left(\frac{1}{Y_{1} M_{1}}\right) \frac{1}{U_{\overline{2}}^{2}}=\left(\frac{X_{1}}{M_{1} V_{1}^{2}+M_{2}^{2}}\right)
$$


Jacobson's relation [8] for sound velocity using the concept of intermolecular free length $\left(\mathrm{L}_{\mathrm{f}}\right)$ is given by,

$$
U_{i m}=\frac{K}{L_{f(\text { mix })} \rho_{\text {mix }}^{1 / 2}}
$$

Where, $\mathrm{K}$ is the temperature dependent constant.

Schaff's [9] developed a theoretical formulae for the expansion of sound velocity in binary mixtures as,

$$
U_{i m}=\frac{U_{\infty}\left(X_{1} S_{1}+X_{2} S_{2}\right)\left(X_{1} B_{1}+X_{2} B_{2}\right)}{V_{M}}
$$

The symbols used in all four relations have their usual meaning.

\section{Results and Discussion:}

The values of sound velocity have been evaluated theoretically using three different methods namely Nomoto, Van-Deal, and CFT. The selected mixture for analysis can be classified as (i) Polar in non polar mixture and (ii) Polar in polar mixture.

\subsection{Choice of binary systems:}

The binary system chosen for this study is Toluene with Benzene, Hexane, Heptane and Cyclohexane at 293.15K. The experimental value of ultrasonic velocity and density of binary mixture of Toluene with Benzene, Hexane, Heptane and Cyclohexane are taken from the work of P.S. Nikam etal. and the sample chosen is mainly due to the availability of the experimental data. Toluene in Benzene, Hexane, Heptane and Cyclohexane at $293.15 \mathrm{~K}$ is discussed. The experimental value of density and ultrasonic velocity for pure components of binary and ternary systems are given in the table [1]. The ultrasonic velocity and excess parameters of toluene with other components are given in table 3 and 4 . The variation of concentration with ultrasonic velocity of Toluene with different components is reported graphically in figure (1-4).

\subsection{Polar in non polar mixture:}

Toluene in Benzene, Heptane and Cyclohexane belongs to this category. The calculated values of Umix $2 / \mathrm{Uidl} 2$ alpha, beta, excess velocity and acoustic impedance for this type of mixtures are given in table [ $2 \& 3]$. The variation of excess velocity and beta with the mole fraction of Toluene is given in fig (5). From the table (2), it is observed that the average percentage deviation of computed ultrasonic velocity using various theories like Nomoto method, Van-deal's ideal mixing method and collision factor theory for the mixtures of Toluene with Benzene are 0.20, 0.20 and 0.55 at the temperature $293.15 \mathrm{~K}$. For the binary mixture Toluene with Heptane the average percentage deviations are $0.65,1.70$, and 5.39 at the temperature $293.15 \mathrm{~K}$, whereas for the binary mixture Toluene with cyclohexane the average percentage deviations are 1.07, 0.90 and 4.1 at $293.15 \mathrm{~K}$. The percentage deviation can be studied on the basis of interaction between the components of mixture. Normally in polar and non-polar mixture there is dipole-induced dipole interaction which is very weak10\&11. Toluene is associated through hydrogen bonding. The mixing of toluene with non polar may results in the breaking of hydrogen bond, thereby promoting dissociation. The positive deviation observed is due to the molecular association and complex formation of molecules where as the negative deviations are due to the molecular dissociation of associative molecules. The magnitude of deviation also depends on concentration $12 \& 13$.In the case of Toluene in Benzene and in Heptane it is found to be less in Nomoto method compared to Van- Deal and CFT method. At higher temperature the deviations do not show smooth variation. So, Nomoto method gives best result in these mixtures. In the case of Toluene in cyclohexane the deviations are found to be less in Nomoto method compared to Van- Deal and CFT method. Since, the adiabatic compressibility decreases gradually in its value with the increase of mole fraction, Van-Deal method gives best result in this mixture.

\subsection{Polar in Polar mixture:}

Toluene in Hexane belongs to this category. The calculated of $\mathrm{U} 2 \mathrm{exp} / \mathrm{U} 2 \mathrm{idl}, \alpha, \beta$, excess velocity and acoustic impedance for this type of mixture are given in table (3) for Toluene in Hexane at $293 \mathrm{~K}$. The variation of excess velocity with the mole fraction of toluene in Hexane is shown in the figure (6). From the tables it is observed that the average percentage deviation of computed ultrasonic velocity using various theories namely Nomoto method, Van-Deal ideal mixing method and CFT method for the mixture of Toluene with Hexane are $0.61,0.47$, and 1.75 at the temperature 293.15K. Toluene in Hexane is found to have a weak dipole-dipole interaction. At low temperature, a very few deviations are found to be negative in both Nomoto and Van- Deal methods. But CFT method shows positive deviations only. Analyzing the percentage deviation of Toluene in Hexane, Van-Deal gives best result at low temperatures and Nomoto method gives good result at high temperature.

\subsection{Choice of ternary systems:}

The ternary systems chosen for this study are Cyclohexane + Toluene +2 -propanol at 293.15K. The experimental value of ultrasonic velocity and density of this ternary mixture are taken from the work of G.Arul etal. . The experimental value of density and ultrasonic velocity for pure components are given in the table (1). From the experimental values in the above mixture of different mole fraction of Cyclohexane and 2-propanol at $293.15 \mathrm{~K}$ has been reported in table (1). The variation of ultrasonic velocity, $\beta$ and excess velocity with concentration of cyclohexane and 2-propanol is reported graphically in figures $(7,8)$. Cyclohexane is a non polar liquid where as toluene and 2-propanol is polar liquids. The calculated values of alpha, beta, excess velocity and excess impedance are positive and decreases in concentration of 2-proponol. Since the components are 
having Zero dipole moments, the dipole-dipole interaction 14 is weak in pure state. The decrease in magnitude of the excess parameters suggests the close packing of molecules inside the shield, which may be brought about by the increasing magnitude of interaction $15 \& 16$. The positive and decrease of excess parameters with increase of 2-propanol concentration is due to a weak bond between a conventional localized hydrogen bond and the formation of charge transfer complex occurring between the components of the mixtures $17 \& 18$. The excess volume studies also confirm the weakening of the dipolar interaction between the components of the liquid mixture19. The increase of concentration in ternary mixtures reduces the beta value which shows that there is a strong interaction in the liquid mixtures.
Table (1): Ultrasonic velocity and Density of pure components for Binary and Ternary mixtures: (293.15K)

\begin{tabular}{|l|l|l|}
\hline \multicolumn{2}{|l|}{} & $\mathbf{2 9 3 . 1 5 K}$ \\
\hline Component & $\begin{array}{l}\text { Density } \\
\rho 10^{3} \mathrm{~kg} \mathrm{~m}^{-3}\end{array}$ & $\begin{array}{l}\text { Velocity } \\
\mathrm{Ums}^{-1}\end{array}$ \\
\hline Toluene & 867 & 1312.4 \\
\hline Benzene & 879 & 1308.5 \\
\hline Heptane & 682 & 1150.2 \\
\hline Cyclohexane & 779 & 1274.6 \\
\hline Hexane & 658 & 1098.0 \\
\hline 2-propanol & 768.5 & 1141.3 \\
\hline
\end{tabular}

Values taken from the work of P.S. Nikam etal and G.Arul etal.

Table (2): Excess parameters in the ternary mixture: (293.15K)

\begin{tabular}{|l|l|l|l|l|l|l|l|}
\hline $\begin{array}{l}\text { Mole } \\
\text { fraction } \\
\mathrm{X}_{1}\end{array}$ & $\begin{array}{c}\text { Mole } \\
\text { fraction } \mathrm{X}_{2}\end{array}$ & $\begin{array}{c}\text { Ultrasonic } \\
\text { velocity } \\
\mathrm{U}_{\text {idl }} \mathrm{ms}^{-1}\end{array}$ & $\begin{array}{c}\mathrm{Uexpt}^{2} / \\
\mathrm{U}_{\text {idl }}^{2}\end{array}$ & $\alpha$ & $\begin{array}{c}\beta \\
\times 10^{-10}\end{array}$ & $\begin{array}{c}\text { Excess } \\
\text { velocity } \\
\left(\mathrm{u}^{\mathrm{E}}\right) \mathrm{ms}^{-2}\end{array}$ & $\begin{array}{c}\text { Excess impedance } \\
\mathrm{Z}^{\mathrm{E}} 10^{3} \mathrm{~kg} / \mathrm{m} 2 / \mathrm{s}\end{array}$ \\
\hline 0.400 & 0.199 & 1249.9 & 0.980 & -0.0196 & 7.832 & -12.3 & 10.88 \\
\hline 0.200 & 0.400 & 1205.4 & 1.0414 & 0.0414 & 8.355 & 24.7 & 9.928 \\
\hline 0.100 & 0.499 & 1186.0 & 1.0696 & 0.0696 & 8.593 & 40.6 & 9.811 \\
\hline 0.001 & 0.599 & 1173.2 & 1.0874 & 0.0874 & 8.747 & 50.2 & 9.744 \\
\hline
\end{tabular}

Table (3): Ultrasonic velocity of Binary mixtures: (293.15K)

\begin{tabular}{|c|c|c|c|c|c|c|c|c|}
\hline \multirow{2}{*}{$\begin{array}{l}\text { Binary } \\
\text { mixtures }\end{array}$} & \multirow{2}{*}{$\begin{array}{l}\text { Mole } \\
\text { fraction } \\
X_{1}\end{array}$} & \multirow{2}{*}{$\begin{array}{l}U_{\text {exp* }} \\
\mathrm{ms}^{-1}\end{array}$} & \multirow{2}{*}{$\begin{array}{l}\text { Nomoto } \\
\mathrm{ms}^{-1}\end{array}$} & \multirow{2}{*}{$\begin{array}{l}\text { Van-Deal } \\
\mathrm{ms}^{-1}\end{array}$} & \multirow{2}{*}{$\begin{array}{l}\text { CFT } \\
\mathrm{ms}^{-1}\end{array}$} & \multicolumn{3}{|c|}{ Percentage Deviation } \\
\hline & & & & & & $\begin{array}{c}\Delta U / U_{\exp } \% \\
\text { Nomoto }\end{array}$ & $\begin{array}{l}\Delta U / U_{\exp } \% \\
\text { Van-Deal }\end{array}$ & $\begin{array}{c}\Delta \mathrm{U}^{\prime} \mathrm{U}_{\exp } \% \\
\text { CFT }\end{array}$ \\
\hline & 0.0412 & 1270.4 & 1273.7 & 1271.6 & 1261.3 & 0.25 & 0.09 & 0.71 \\
\hline & 0.1729 & 1274.4 & 1273.1 & 1274.5 & 1268.1 & 0.10 & 0.07 & 0.49 \\
\hline Toluene & 0.3580 & 1277.3 & 1276.1 & 1276.6 & 1270.7 & 0.08 & 0.53 & 0.51 \\
\hline+ benzene & 0.5565 & 1280.7 & 1278.1 & 1273.5 & 1277.1 & 0.20 & 0.58 & 0.28 \\
\hline & 0.6623 & 1305.0 & 1289.1 & 1277.6 & 1287.1 & 1.21 & 2.09 & 1.37 \\
\hline & 0.0677 & 1161.2 & 1158.1 & 1147.6 & 1101.2 & 0.23 & 1.17 & 5.16 \\
\hline & 0.2560 & 1192.0 & 1195.6 & 1183.4 & 1134.2 & 0.30 & 1.31 & 5.40 \\
\hline Toluene & 0.4798 & 1238.6 & 1233.6 & 1216.0 & 1172.0 & 0.40 & 1.82 & 5.37 \\
\hline + Heptane & 0.6744 & 1281.6 & 1266.0 & 1254.7 & 1206.1 & 1.21 & 2.09 & 5.89 \\
\hline & 0.8465 & 1322.1 & 1308.4 & 1296.6 & 1251.5 & 1.02 & 1.93 & 2.33 \\
\hline & 0.0677 & 1125.7 & 1118.6 & 1120.3 & 1110.2 & 0.63 & 0.47 & 1.37 \\
\hline Toluene + & 0.2566 & 1158.3 & 1146.2 & 1150.1 & 1140.3 & 1.04 & 0.70 & 1.55 \\
\hline
\end{tabular}




\begin{tabular}{|l|l|l|l|l|l|l|l|l|}
\hline Cyclohexane & 0.4793 & 1195.8 & 1175.2 & 1189.3 & 1186.4 & 1.70 & 0.54 & 0.77 \\
\hline & 0.6744 & 1228.5 & 1215.4 & 1210.5 & 1220.7 & 1.06 & 1.46 & 0.63 \\
\hline & 0.8467 & 1258.3 & 1241.9 & 1240.6 & 1240.6 & 1.30 & 1.40 & 1.12 \\
\hline & & & & & & & & \\
\hline & 0.0609 & 1070.9 & 1075.6 & 1069.0 & 1055.4 & -0.43 & 0.17 & 1.44 \\
\hline Toluene & 0.2355 & 1106.1 & 1101.1 & 1083.1 & 1096.2 & 0.42 & 0.07 & 0.89 \\
\hline & 0.4509 & 1161.1 & 1150.0 & 1129.8 & 1130.4 & 0.96 & 0.47 & 2.64 \\
\hline & 0.6489 & 1199.6 & 1184.0 & 1169.8 & 1180.0 & 1.30 & 1.10 & 1.63 \\
\hline & 0.8313 & 1238.0 & 1226.1 & 1230.2 & 1211.4 & 0.96 & 0.61 & 2.15 \\
\hline
\end{tabular}

Table (4): Excess parameters in the Binary mixture: (293.15K)

\begin{tabular}{|c|c|c|c|c|c|c|c|}
\hline Mixture & $\begin{array}{c}\text { Mole } \\
\text { fraction } \\
X_{1}\end{array}$ & $\begin{array}{l}\text { Ultrasonic } \\
\text { velocity } \\
\mathrm{U}_{\text {idl }} \mathrm{ms}^{-1}\end{array}$ & $\begin{array}{l}U^{2} \exp / U^{2} \\
\text { dl }\end{array}$ & $\alpha$ & $\begin{array}{c}\beta \\
\times 10^{-10}\end{array}$ & $\begin{array}{l}\text { Excess } \\
\text { velocity } \\
\left(\mathrm{u}^{\mathrm{E}}\right) \mathrm{ms}^{-2}\end{array}$ & $\begin{array}{l}\text { Excess impedance } \\
\mathrm{Z}^{\mathrm{E}} 10^{3} \mathrm{~kg} / \mathrm{m} 2 / \mathrm{s}\end{array}$ \\
\hline $\begin{array}{c}\text { Toluene } \\
+ \\
\text { Benzene }\end{array}$ & $\begin{array}{l}0.0412 \\
0.1729 \\
0.3580 \\
0.5565 \\
0.7699\end{array}$ & $\begin{array}{l}1271.6 \\
1274.5 \\
1274.6 \\
1273.2 \\
1277.6\end{array}$ & $\begin{array}{l}0.9980 \\
0.9998 \\
1.0010 \\
1.0118 \\
1.0433\end{array}$ & $\begin{array}{c}-0.0020 \\
-0.0002 \\
0.0012 \\
0.0118 \\
0.0433\end{array}$ & $\begin{array}{l}7.2007 \\
7.1823 \\
7.1778 \\
7.2352 \\
7.2045\end{array}$ & $\begin{array}{c}-1.25 \\
-0.09 \\
0.68 \\
7.50 \\
27.39\end{array}$ & $\begin{array}{l}10.92 \\
10.92 \\
10.91 \\
10.85 \\
10.86\end{array}$ \\
\hline $\begin{array}{c}\text { Toluene } \\
+ \\
\text { Heptane }\end{array}$ & $\begin{array}{l}0.0677 \\
0.2560 \\
0.4798 \\
0.6744 \\
0.8461\end{array}$ & $\begin{array}{l}1147.6 \\
1183.4 \\
1216.0 \\
1254.7 \\
1296.6\end{array}$ & $\begin{array}{l}1.0238 \\
1.0268 \\
1.0375 \\
1.0433 \\
1.0397\end{array}$ & $\begin{array}{l}0.0238 \\
0.0268 \\
0.0375 \\
0.0433 \\
0.0397\end{array}$ & $\begin{array}{l}10.856 \\
09.826 \\
08.875 \\
07.994 \\
07.157\end{array}$ & $\begin{array}{l}13.6 \\
15.8 \\
41.1 \\
26.9 \\
25.5\end{array}$ & $\begin{array}{l}8.026 \\
8.599 \\
9.608 \\
9.969 \\
10.77\end{array}$ \\
\hline $\begin{array}{c}\text { Toluene } \\
+ \\
\text { Cyclohexane }\end{array}$ & $\begin{array}{l}0.0677 \\
0.2566 \\
0.4793 \\
0.6744 \\
0.8467\end{array}$ & $\begin{array}{l}1120.3 \\
1150.1 \\
1189.3 \\
1210.5 \\
1240.6\end{array}$ & $\begin{array}{l}1.0096 \\
1.0013 \\
1.0019 \\
1.0299 \\
1.0287\end{array}$ & $\begin{array}{l}0.0096 \\
0.0143 \\
0.0109 \\
0.0299 \\
0.0287\end{array}$ & $\begin{array}{l}11.772 \\
10.741 \\
09.555 \\
08.795 \\
08.001\end{array}$ & $\begin{array}{c}5.4 \\
8.2 \\
6.5 \\
7.8 \\
17.7\end{array}$ & $\begin{array}{l}7.582 \\
8.094 \\
8.797 \\
9.392 \\
9.840\end{array}$ \\
\hline $\begin{array}{c}\text { Toluene } \\
+ \\
\text { Hexane }\end{array}$ & $\begin{array}{l}0.0609 \\
0.2355 \\
0.4509 \\
0.6489 \\
0.8313\end{array}$ & $\begin{array}{l}1069.0 \\
1105.2 \\
1155.6 \\
1186.3 \\
1230.6\end{array}$ & $\begin{array}{l}1.0035 \\
1.0015 \\
1.0096 \\
1.0225 \\
1.0124\end{array}$ & $\begin{array}{l}0.0035 \\
0.0115 \\
0.0096 \\
0.0225 \\
0.0124\end{array}$ & $\begin{array}{l}13.380 \\
11.856 \\
10.320 \\
09.272 \\
08.182\end{array}$ & $\begin{array}{l}1.89 \\
0.87 \\
5.55 \\
13.3 \\
7.62\end{array}$ & $\begin{array}{l}6.990 \\
7.566 \\
8.384 \\
9.091 \\
9.932\end{array}$ \\
\hline
\end{tabular}


Fig (1)

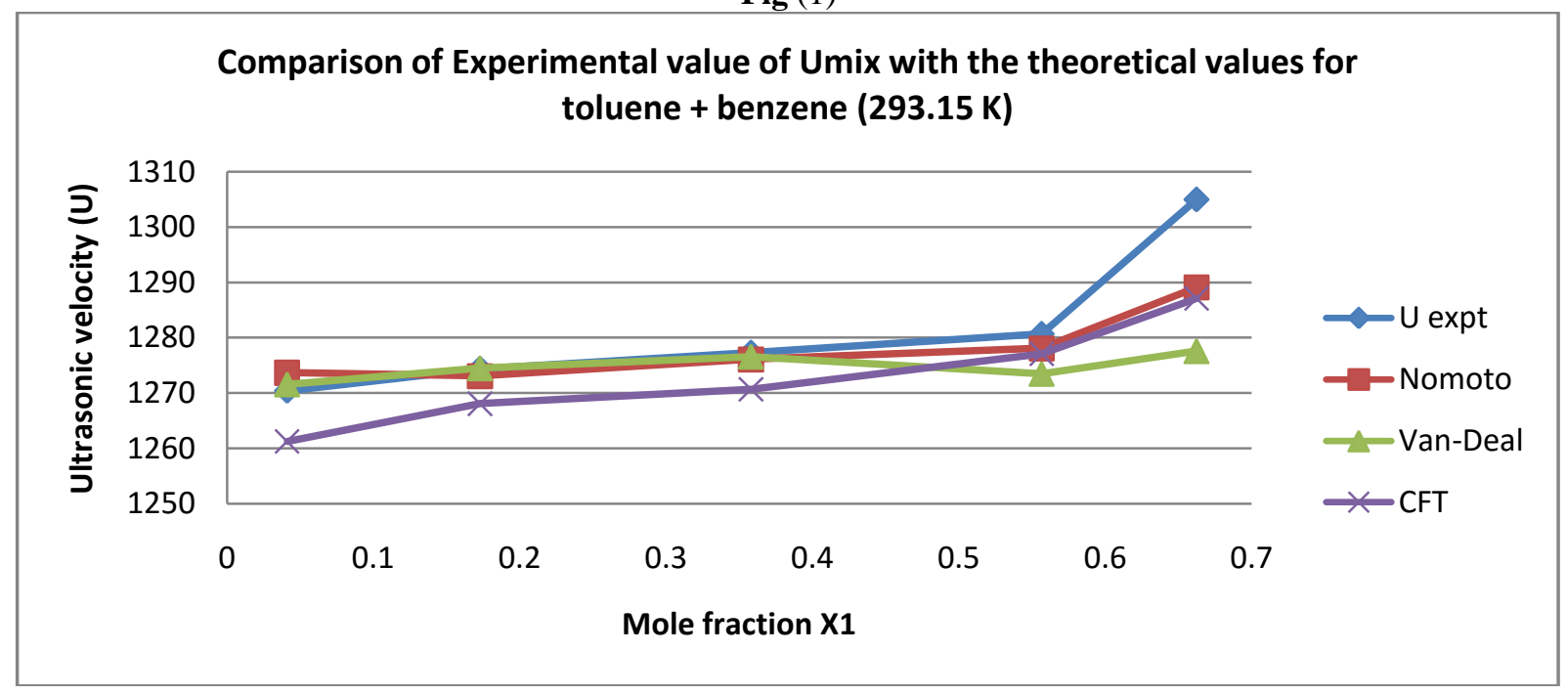

Fig (2)

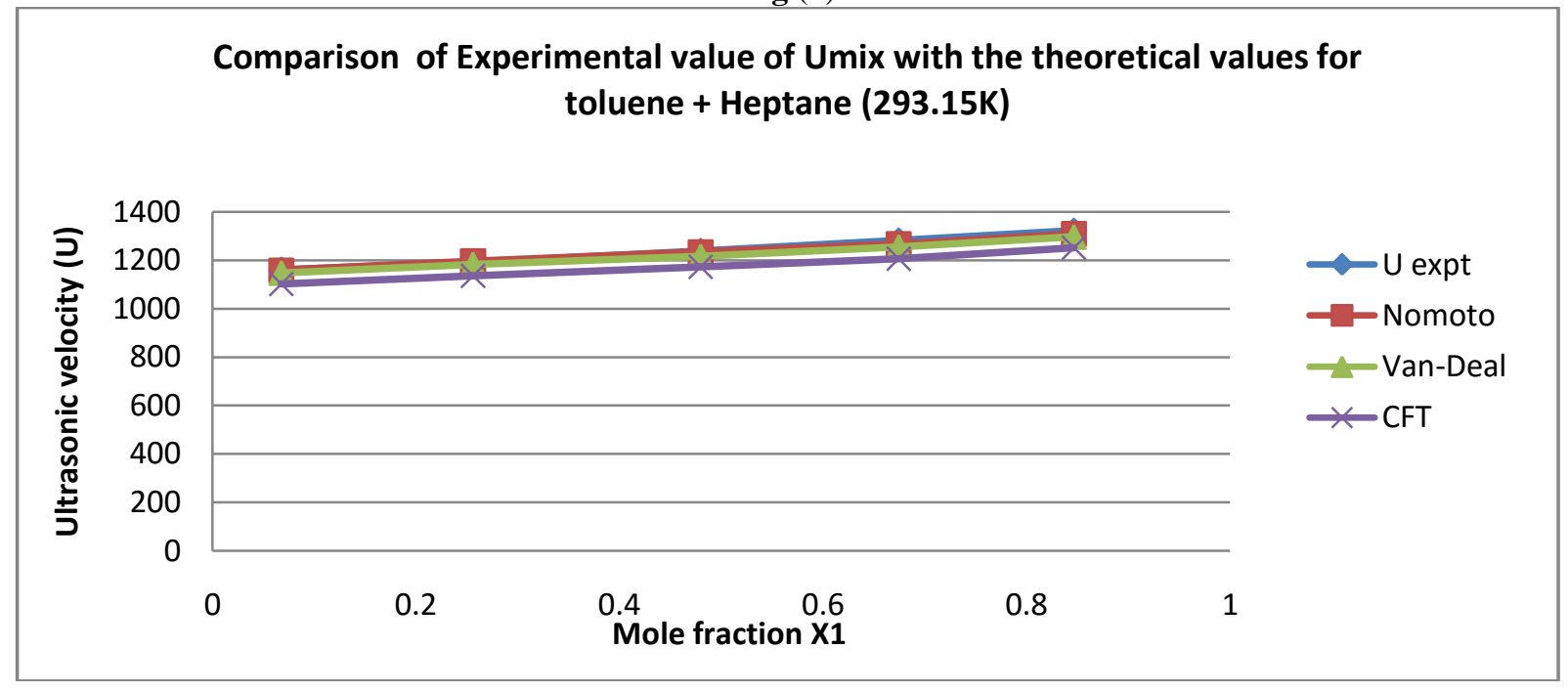

Fig (3)

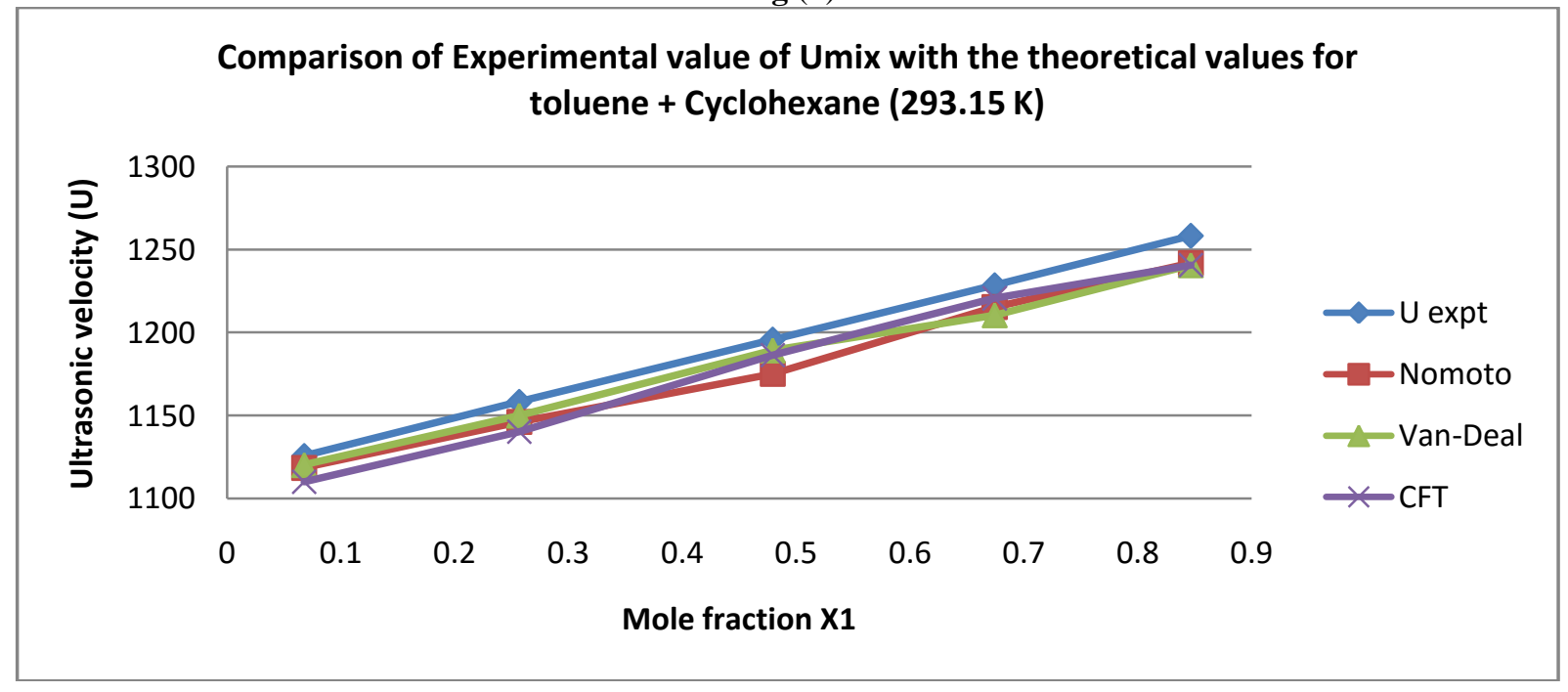


Fig (4)

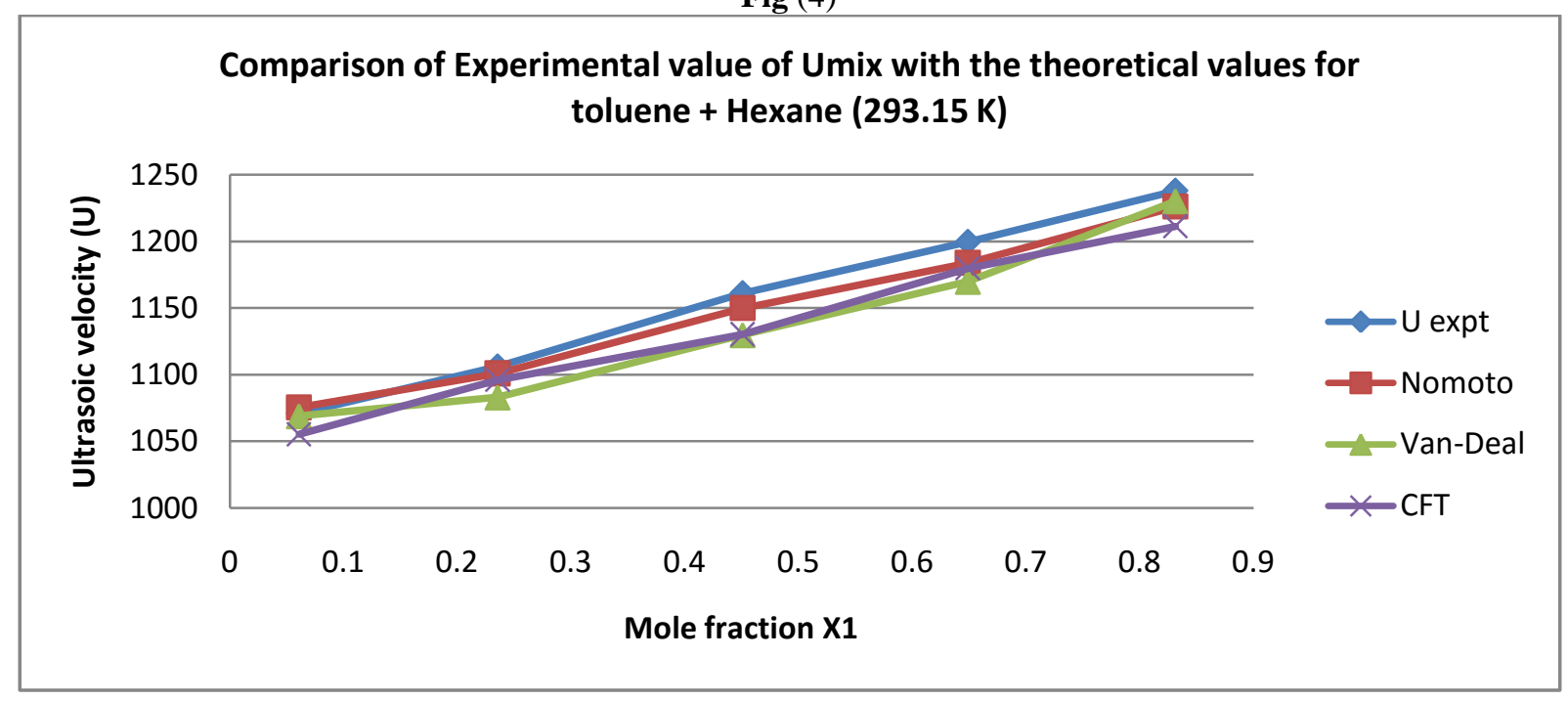

Fig (5)

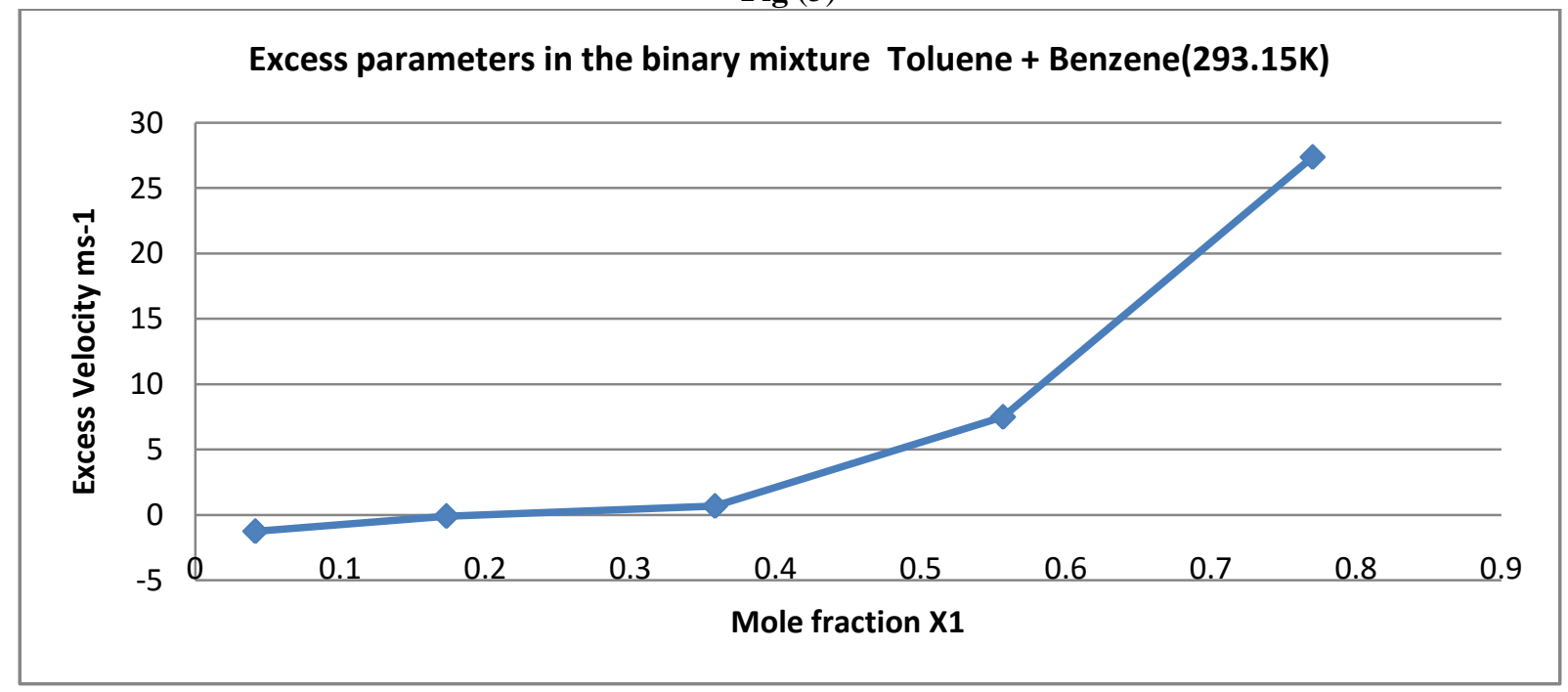

Fig (6)

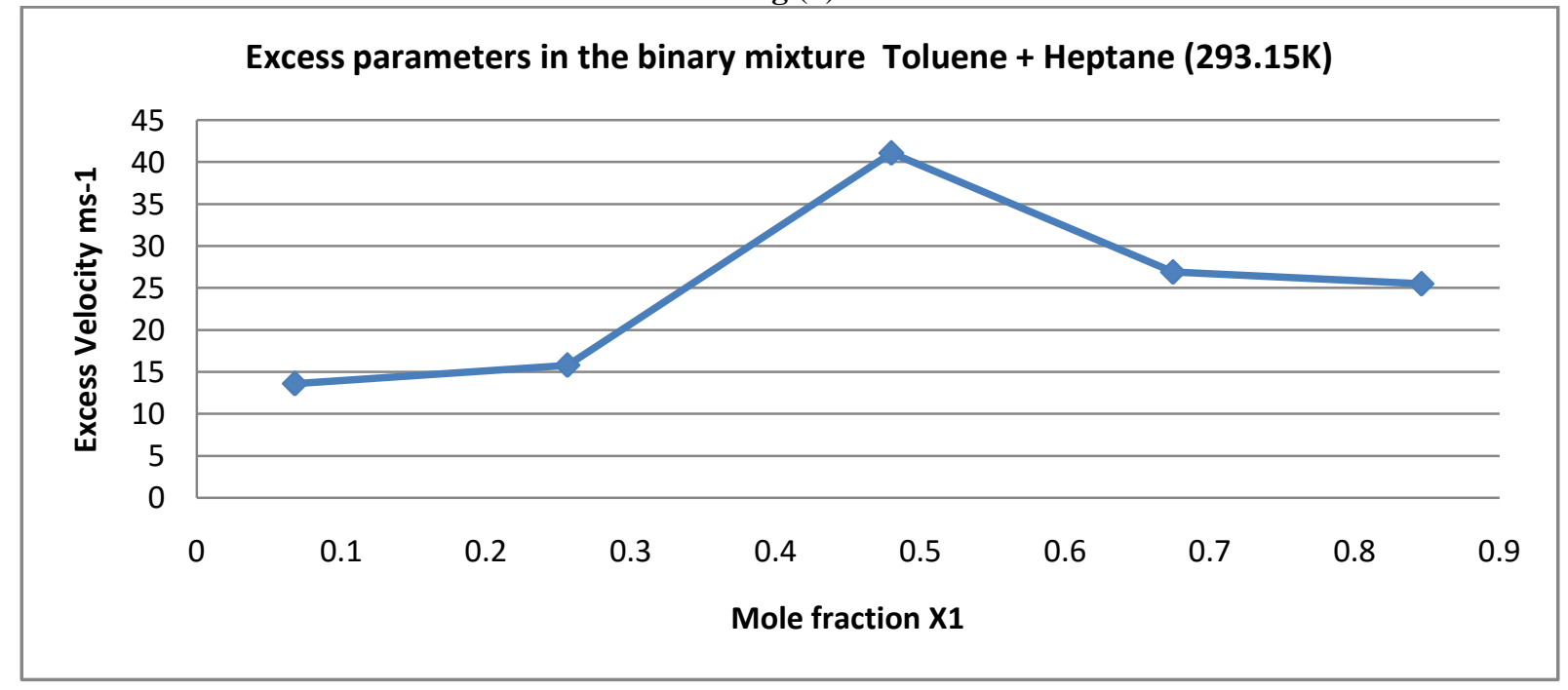


Fig (7)

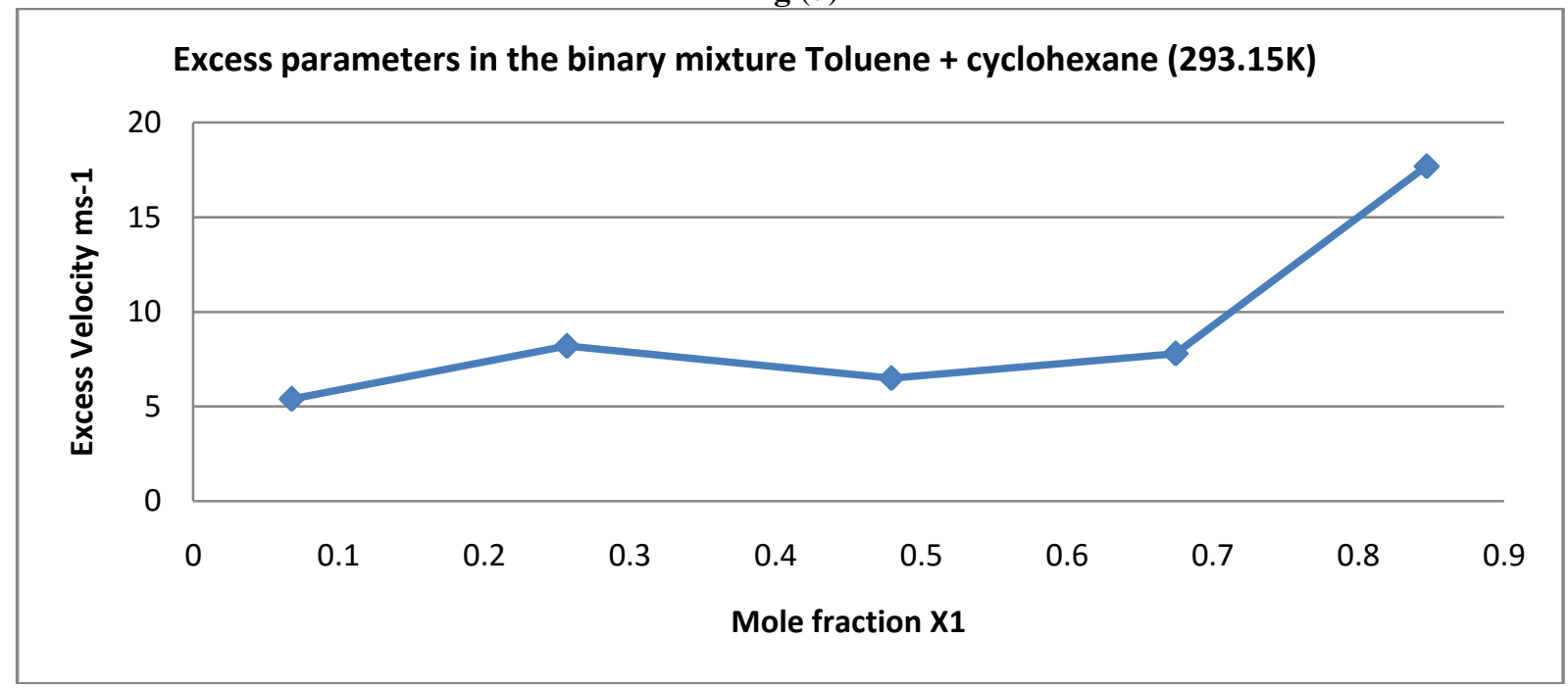

Fig (8)

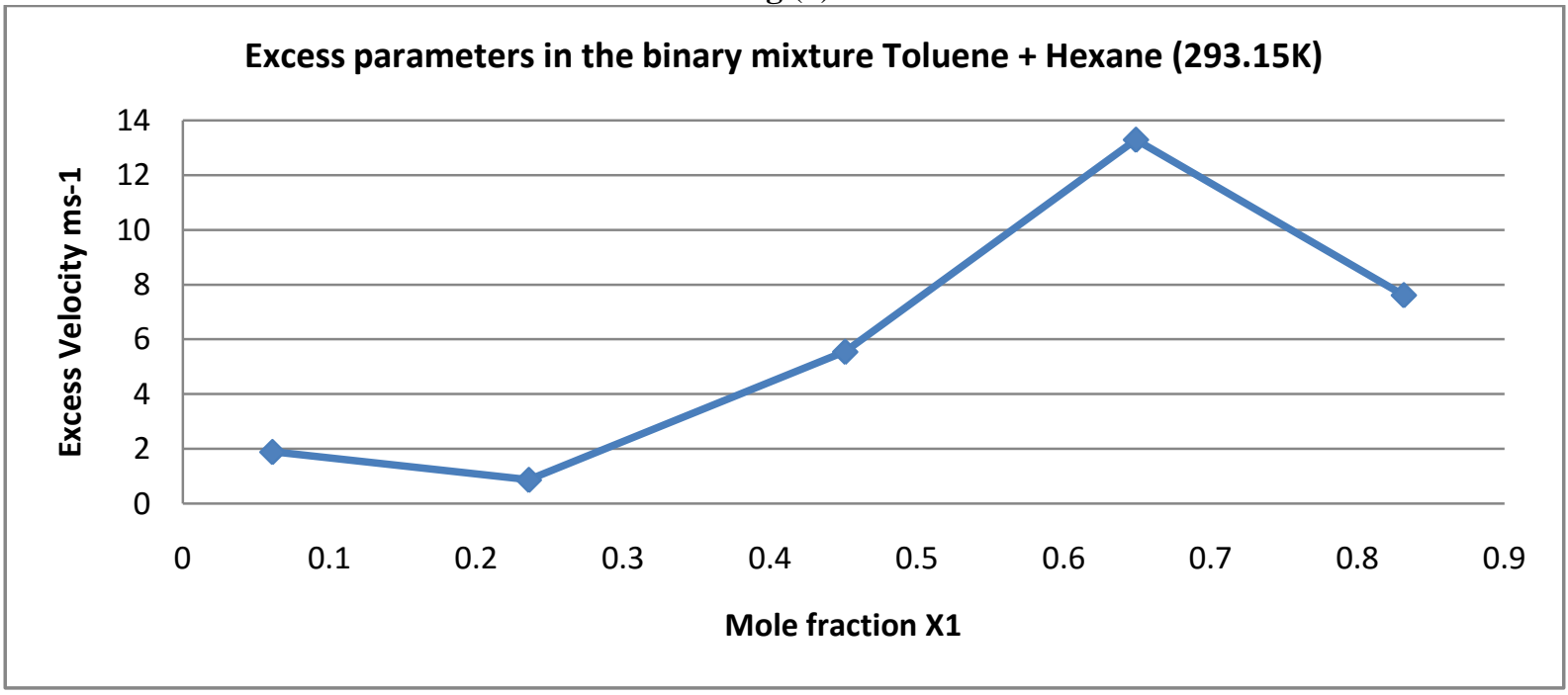

\section{CONCLUSION}

The percentage deviation can be studied on the basis of interaction between the components of mixtures. Normally in polar and non polar mixtures there is dipole-induced dipole which is very weak. This type of mixture also results in the breaking of hydrogen bond thereby promoting dissociation. The positive deviation observed is due to the molecular association and complex formation of molecules, whereas the negative deviation is due to the molecular dissociation of associative molecules. The magnitude of deviation also depends on concentration. In ternary mixture the decrease of magnitude of excess parameter suggest the close packing of molecules inside the shield which may be brought about by the increase in magnitude of interaction. The increase of concentration in ternary mixture reduces the beta value which shows that there is strong interaction in liquid mixtures. This work is found to be quite interesting and out of three different methods Nomato methods is found to be the best one due to the closeness of the value observed with respect to the experimental one.

\section{REFERENCES}

[1] A.P. Kaoustin, N.T. Bykova, Sov. Prim. Utra akust, 22,1149 (1967)

[2] A.P. Kaoustin, N.T. Bykova, Sov. Phys. Gustallogra 13,281 (1968)

[3] Pandey.J.D Shukla A.K, Pant, Sarika and Krishan. V. Ind, J.Pure and Appl.Phys. 27,246 (1989)

[4] S.Singh, R.Singh, N.Prasad and S. Prakas, Ind, J.Pure and Appl.Phys.15,629 (1977)

[5] Pandey.J.D, Ranjan Dey and David.D.K Pramana J. Phys 52, 87 (1999)

[6] Nomato.J.Phys.Soc, 13,1528 (1958).

[7] Van-Deal W (1978) Thermodynamics properties and velocity of sound (London: Better Worth) Ch. 5.

[8] Jacobson B, J Chem., Phys., 19, 927 (1950). 
[9] Schaffs W, Molecular Acoustic Chapter X1 and X11 (Springer Berline) (1963).

[10] Kannappan A.N., Ramalingam k and Palani R Ind, J. Pure and Appl.Phys. 29,43 (1991).

[11] Srinivasta A.P Ind, J, Chem.., 31 A, 557 (1992)

[12] Jacobson B, J Chem., Phys., 19, 927 (1950).

[13] Jacobson B, Octa Chem., Scand., 5, 244 (1951).

[14] Rajasekar.J. and Naidu. P.R.J.Chem. Eng data 41, 373 (1996).

[15] Arul G \& Palniappan L.J. Acoust Soc ind, 28, 393 (2000).

[16] Kalidoss. M and Srinivasamoorthy R.J. Jol. Pure and Appl Ultrasonics, 199 (1997).

[17] Pandey J.D and Shukla A.K.J Pure and Appl Ultrasonics, 15, 37 (1997).

[18] Nikam P.S. Mahale T.R \& Mejdi Hasan, Indian J.Pure and Appl Phys. 37, 92 (1999).

[19] Sadasiva Roa A. Viyayakumar Naidu B and Chowdoji Roa K.J Acoust Sco Ind. 28, 303 (2000).

[20] Tiwari K.Patra C and Chacravorthy V. Acoust Lett.6, 53 (1995). 